\title{
A three-dimensional open-framework indium selenide: [C7H10N][In9Se14]
}

Article

Accepted Version

Vaqueiro, P. (2008) A three-dimensional open-framework indium selenide: [C7H10N][In9Se14]. Inorganic Chemistry, 47 (1). pp. 20-22. ISSN 0020-1669 doi: https://doi.org/10.1021/ic701995p Available at https://centaur.reading.ac.uk/34234/

It is advisable to refer to the publisher's version if you intend to cite from the work. See Guidance on citing.

Published version at: http://pubs.acs.org/doi/abs/10.1021/ic701995p

To link to this article DOI: http://dx.doi.org/10.1021/ic701995p

Publisher: American Chemical Society

All outputs in CentAUR are protected by Intellectual Property Rights law, including copyright law. Copyright and IPR is retained by the creators or other copyright holders. Terms and conditions for use of this material are defined in the End User Agreement.

\section{www.reading.ac.uk/centaur}

\section{CentAUR}

Central Archive at the University of Reading

Reading's research outputs online 


\title{
A three-dimensional open-framework indium selenide: $\left[\mathrm{C}_{7} \mathrm{H}_{10} \mathrm{~N}\right]\left[\mathrm{In}_{9} \mathrm{Se}_{14}\right]$
}

\author{
Paz Vaqueiro \\ Department of Chemistry, Heriot-Watt University, Edinburgh EH14 4AS, UK \\ RECEIVED DATE (will be automatically inserted after manuscript is accepted)
}

ABSTRACT An open-framework indium selenide, $\left[\mathrm{C}_{7} \mathrm{H}_{10} \mathrm{~N}\right]\left[\mathrm{I}_{9} \mathrm{Se}_{14}\right]$, has been prepared under solvothermal conditions in the presence of 3,5dimethylpyridine, and characterized by single crystal diffraction, thermogravimetry, elemental analysis, FTIR spectroscopy and UV-Vis diffuse reflectance. The crystal structure of $\left[\mathrm{C}_{7} \mathrm{H}_{10} \mathrm{~N}\right]\left[\mathrm{In}_{9} \mathrm{Se}_{14}\right]$ contains an unusual building unit, in which corner-linked and edgelinked $\mathrm{InSe}_{4}{ }^{5-}$ tetrahedra coexist. The presence of one-dimensional circular channels, of ca. $6 \AA$ diameter, results in approximately $25 \%$ of solvent accessible void space.

There have been extensive research efforts to develop new microporous materials during the last few decades, because of their technological importance for applications such as catalysis or molecular sieves. ${ }^{1}$ Although research has focused primarily on oxygen-based frameworks, in recent years there has been an increasing interest in the preparation of microporous chalcogenide materials, ${ }^{2}$ given their technological potential as multifunctional materials, capable of combining the ion-exchanging and catalytic features of zeolites with the semiconducting behaviour of metal chalcogenides. Possible areas of application for these novel microporous semiconductors range from molecule discriminating sensors ${ }^{3}$ to selective ion-exchange $e^{4}$ and photocatalysis. ${ }^{5}$ A significant progress has already been made in the synthesis of open-framework indium sulphides built from supertetrahedral clusters, which can be described as tetrahedrally shaped fragments of the $\mathrm{ZnS}$ structure. ${ }^{6} \mathrm{In}$ comparison with sulfides, very few indium selenides are known, but their development is desirable to allow tuning of the electronic and optical properties of the resulting chalcogenides. Given that selenides and tellurides tend to have higher electrical conductivities (and smaller band gaps) than sulfides and that the disorder of the template generally found in microporous chalcogenides may lead to low thermal conductivities, ${ }^{7}$ these materials could also find applications in the area of thermoelectricity.

The very few examples of microporous indium selenides reported so far have revealed a greater degree of structural complexity than that found in the corresponding indium sulfides. While the three-dimensional structure of the
$\left[\mathrm{In}_{10} \mathrm{Se}_{18}\right]^{6-}$ open-framework ${ }^{8}$ exhibits a supertetrahedrabased double-diamond lattice, isostructural to the indium sulphide $\left[\left(\mathrm{CH}_{3}\right)_{2} \mathrm{NH}_{2}\right]\left[\mathrm{In}_{10} \mathrm{~S}_{18}\right],{ }^{9}$ and that of $\left[\mathrm{In}_{4} \mathrm{Se}_{8}\right]^{4-}$ can be described as a non-interpenetrating supertetrahedra-based diamond lattice, ${ }^{10}$ the $\left[\mathrm{In}_{33} \mathrm{Se}_{56}\right]^{13-}$ open-framework ${ }^{11}$ does not contain supertetrahedral clusters. Instead the structure of $\left[\operatorname{In}_{33} \mathrm{Se}_{56}\right]^{13-}$ can be described as formed by cross-linked chains of corner-sharing $\operatorname{InSe}_{4}{ }^{5-}$ tetrahedra. ${ }^{11}$ In $\left[\mathrm{NH}_{4}\right]_{4}\left[\mathrm{In}_{12} \mathrm{Se}_{20}\right]$, nona-nuclear indium clusters are the building units of a microporous structure which exhibits ion-exchange properties with heavy-metal ions. ${ }^{12}$

Here we report the synthesis, crystal structure ${ }^{13}$ and optical properties ${ }^{14}$ of a three-dimensional open-framework indium selenide, $\left[\mathrm{C}_{7} \mathrm{H}_{10} \mathrm{~N}\right]\left[\mathrm{In}_{9} \mathrm{Se}_{14}\right]$. The unique crystal structure of this material contains an unusual building unit, in which corner-linked and edge-linked $\mathrm{InSe}_{4}{ }^{5-}$ tetrahedra coexist. To prepare $\left[\mathrm{C}_{7} \mathrm{H}_{10} \mathrm{~N}\right]\left[\mathrm{In}_{9} \mathrm{Se}_{14}\right], \quad 3,5-$ dimethylpyridine (Aldrich, 98+\%, $2.5 \mathrm{~mL}, 21.9 \mathrm{mmol}$ ) was added to a Teflon-lined $23 \mathrm{ml}$ stainless steel autoclave containing indium metal (Aldrich, 99.99\%, $168 \mathrm{mg}, 1.46$ mmol) and selenium (Aldrich, 99.5\%, $196 \mathrm{mg}, 2.48 \mathrm{mmol}$ ). The vessel was sealed and heated at $200^{\circ} \mathrm{C}$ for 16 days. After cooling to room temperature overnight, the reaction mixture was filtered, washed with ethanol and acetone and dried in air at room temperature. The reaction product consists of red needles of $\left[\mathrm{C}_{7} \mathrm{H}_{10} \mathrm{~N}\right]\left[\mathrm{In}_{9} \mathrm{Se}_{14}\right]$ together with an amorphous brown powder. The red needles of $\left[\mathrm{C}_{7} \mathrm{H}_{10} \mathrm{~N}\right]\left[\mathrm{In}_{9} \mathrm{Se}_{14}\right]$ were separated from the brown powder using an ultrasonic bath, and further purified by handpicking of crystals under a microscope.

The crystal structure of $\left[\mathrm{C}_{7} \mathrm{H}_{10} \mathrm{~N}\right]\left[\mathrm{In}_{9} \mathrm{Se}_{14}\right]$ (Table 1) contains two crystallographically independent indium atoms, which are tetrahedrally coordinated by selenium atoms (Figure 1). The In-Se distances lie in the range 2.5243(9)-2.6669(6) $\AA$, similar to those reported for other indium selenides containing tetrahedrally coordinated $\mathrm{In}^{15}$ The $\mathrm{InSe}_{4}{ }^{5-}$ tetrahedra are significantly distorted as evidenced by $\mathrm{Se}-\mathrm{In}-\mathrm{Se}$ angles varying between 128.83(2) and $94.34(2)^{\circ}$ for $\operatorname{In}(1)$ and between 136.38(5) and $98.52(3)$ for $\operatorname{In}(2)$. The building unit of the $\left[\operatorname{In}_{9} \mathrm{Se}_{14}\right]^{-}$ framework is a six-membered $\mathrm{In}_{3} \mathrm{Se}_{3}$ ring, formed by corner-linked $\mathrm{InSe}_{4}{ }^{5-}$ tetrahedra. Each $\mathrm{In}(1) \mathrm{Se}_{4}{ }^{5-}$ tetrahedron in the $\mathrm{In}_{3} \mathrm{Se}_{3}$ ring shares an edge with a second $\operatorname{In}(1) \mathrm{Se}_{4}{ }^{5-}$ tetrahedron of an adjacent ring, forming a chain which runs 
parallel to the $c$-axis (Figure 2). While all solvothermallyprepared indium selenides reported to date are built from corner-linked $\mathrm{InSe}_{4}{ }^{5-}$ tetrahedra, edge-linked tetrahedra have been previously found in condensed structures, such as TlInSe ${ }_{2}{ }^{16}$ Edge-sharing of $\mathrm{InSe}_{4}{ }^{5-}$ tetrahedra results in relatively short In-In distances, of $c a .3 .58$ and $3.42 \AA$ in the title compound and $\mathrm{Tl} I n \mathrm{Se}_{2}$ respectively. Much shorter In-In distances ( $c a .2 .77 \AA$ ) have been however found in indium-rich selenides such as $\mathrm{InSe}^{17}$ or $\mathrm{In}_{4} \mathrm{Se}_{3} .{ }^{18}$ This suggests that In-In interactions in the title compound are very weak.

Table 1. Crystallographic data for $\left[\mathrm{C}_{7} \mathrm{H}_{10} \mathrm{~N}\right]\left[\mathrm{In}_{9} \mathrm{Se}_{14}\right]$.

\begin{tabular}{|l|l|}
\hline$M_{r}$ & 2138.82 \\
\hline Crystal system & Hexagonal \\
\hline Space group & $P 6_{3} / m$ \\
\hline $\mathrm{T} / \mathrm{K}$ & 100 \\
\hline$a / \AA$ & $12.8786(6)$ \\
\hline$c / \AA$ & $11.7792(12)$ \\
\hline $\mathrm{V} / \AA^{3}$ & $1691.9(2)$ \\
\hline $\mathrm{Z}$ & 2 \\
\hline$\mu / \mathrm{mm}^{-1}$ & 21.066 \\
\hline Measured data & 43944 \\
\hline Unique data & 1470 \\
\hline Observed data $(\mathrm{I}>3 \sigma(\mathrm{I}))$ & 958 \\
\hline $\mathrm{R}_{\text {merg }}$ & 0.039 \\
\hline $\mathrm{R}$ & 0.0202 \\
\hline $\mathrm{R}_{\mathrm{W}}$ & 0.0223 \\
\hline
\end{tabular}

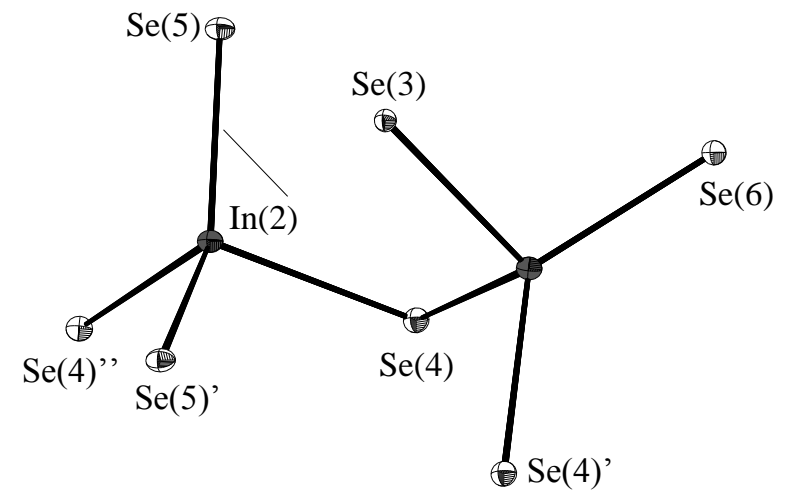

Figure 1. Local coordination diagram showing the atoms labeling scheme and ellipsoids at $50 \%$ probability.

The individual chains shown in Fig. 2 are linked into a three-dimensional honeycomb structure by sharing the terminal $\mathrm{Se}(3)$ and $\mathrm{Se}(5)$ atoms with four adjacent chains (Figure 3). These individual chains are related to each other by $120^{\circ}$ rotations around the three-fold axes located at $1 / 3$, $2 / 3, z$ and $2 / 3,1 / 3, z$. Large circular channels of $c a .9 \AA$ (measured from coordinate to coordinate) are formed parallel to the $c$-axis. When the van der Waals radii of In and $\mathrm{Se}$ are taken into account, the effective aperture dimension of the channels is $c a .6 \AA$. Using PLATON, ${ }^{19}$ it was established that the $\left[\mathrm{In}_{9} \mathrm{Se}_{14}\right]^{-}$framework contains $c a$. $25 \%$ of solvent accessible void space. The 3,5dimethylpyridine molecules are therefore assumed to be located within the channels and, given the anionic nature of the framework, protonated for charge balance. The FTIR spectrum (Supplementary Information) of the title compound is consistent with the presence of aromatic and amine functional groups. A peak at $c a .3450 \mathrm{~cm}^{-1}$ can be tentatively assigned to $\mathrm{N}-\mathrm{H}$ stretching vibrations, those at ca. $3000 \mathrm{~cm}^{-1}$ can be attributed to $\mathrm{C}-\mathrm{H}$ stretching vibrations, while those over the region $1600-1400 \mathrm{~cm}^{-1}$ are characteristic of aromatic compounds. Elemental analysis is also consistent with the presence of one protonated 3,5,dimethylpyridinium cation per formula unit. ${ }^{20}$

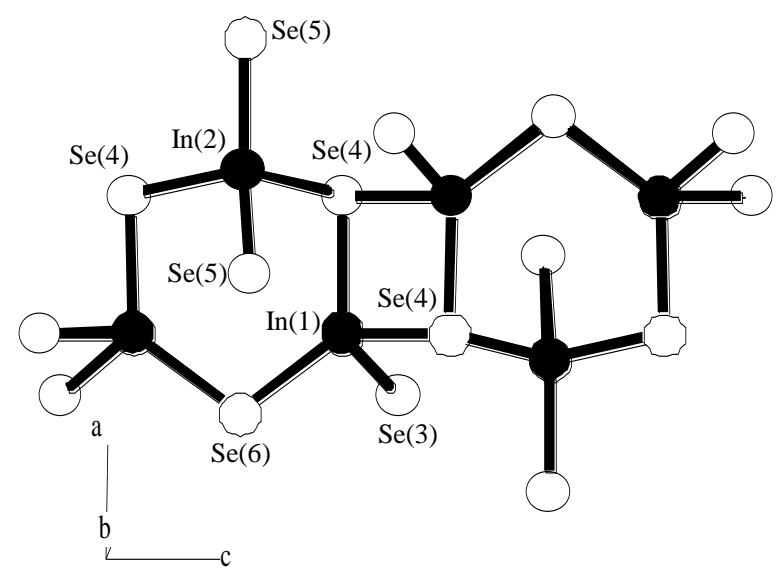

Figure 2. $\operatorname{In}_{3} \mathrm{Se}_{7}{ }^{5-}$ chains running parallel to the $c$ axis. The labeling scheme is shown.

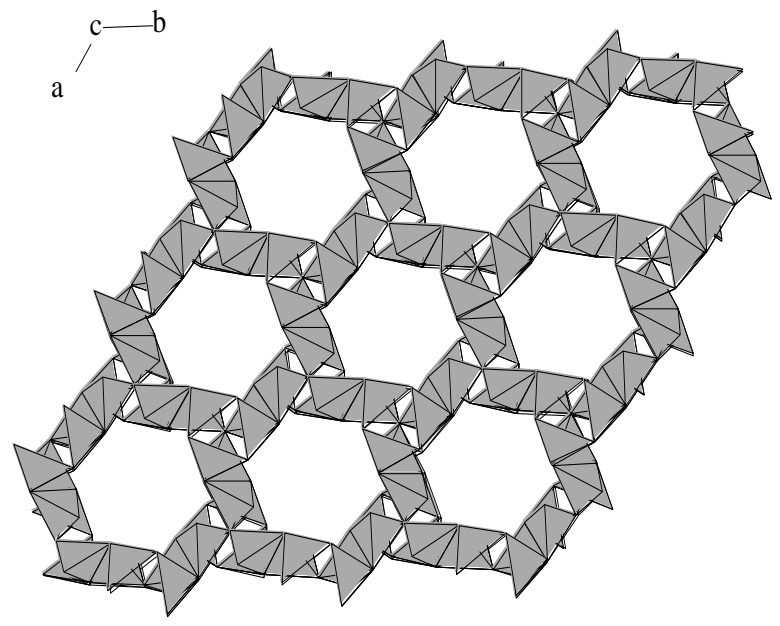

Figure 3. Polyhedral representation of the $\left[\mathrm{C}_{7} \mathrm{H}_{10} \mathrm{~N}\left[\mathrm{In}_{9} \mathrm{Se}_{14}\right]\right.$ structure viewed along [001]. The 3,5-dimethylpyridinium cations are disordered and located within the one-dimensional channels of the $\left[\mathrm{In}_{9} \mathrm{Se}_{14}\right]^{-}$ framework.

Thermogravimetric analysis ${ }^{21}$ indicates that, under a nitrogen atmosphere, $\left[\mathrm{C}_{7} \mathrm{H}_{10} \mathrm{~N}\right]\left[\mathrm{In}_{9} \mathrm{Se}_{14}\right]$ is stable up to $c a$. $250^{\circ} \mathrm{C}$ (Supplementary Information). The weight loss $(6.0 \%)$ is larger than that expected for the total removal of the amine (calculated 4.8\%). This may indicate the concomitant loss of a fraction ( $c a .2 .4$ at.\%) of the selenium, which would result in a decomposition product with a composition close to $\operatorname{In}_{2} \mathrm{Se}_{3}$. Although heating of open-framework chalcogenides often results in the collapse of the crystal structure, a number of studies ${ }^{4,12,22}$ have 
demonstrated that ion exchange can be used for the removal of the organic species. This suggests that it may be possible to access the microporosity of $\left[\mathrm{C}_{7} \mathrm{H}_{10} \mathrm{~N}\right]\left[\mathrm{In}_{9} \mathrm{Se}_{14}\right]$ by ion exchange.

The optical absorption spectrum of the title compound is shown in Figure 4. The band gap, which was estimated from the absorption edge, has a value of $1.91(6) \mathrm{eV}$. This is consistent with the red color of $\left[\mathrm{C}_{7} \mathrm{H}_{10} \mathrm{~N}\right]\left[\mathrm{In}_{9} \mathrm{Se}_{14}\right]$, and confirms the semiconducting nature of this material. The band gap of $\left[\mathrm{C}_{7} \mathrm{H}_{10} \mathrm{~N}\right]\left[\mathrm{In}_{9} \mathrm{Se}_{14}\right]$ lies within the energy range suitable for photocatalytic applications using light in the visible region, ${ }^{5}$ and is comparable to those found for other microporous indium selenides. ${ }^{12}$ However, when compared with condensed phases such as $\alpha-\mathrm{In}_{2} \mathrm{Se}_{3}\left(\mathrm{E}_{\mathrm{g}} \approx 1.4 \mathrm{eV}\right),{ }^{23}$ the title compound as well as the small number of known microporous indium selenides, exhibit larger band gaps. It has been proposed that there is a correlation between the magnitude of the optical band gap and the framework density, through analysis of data for a wide range of antimony sulfides of differing dimensionality. ${ }^{24}$

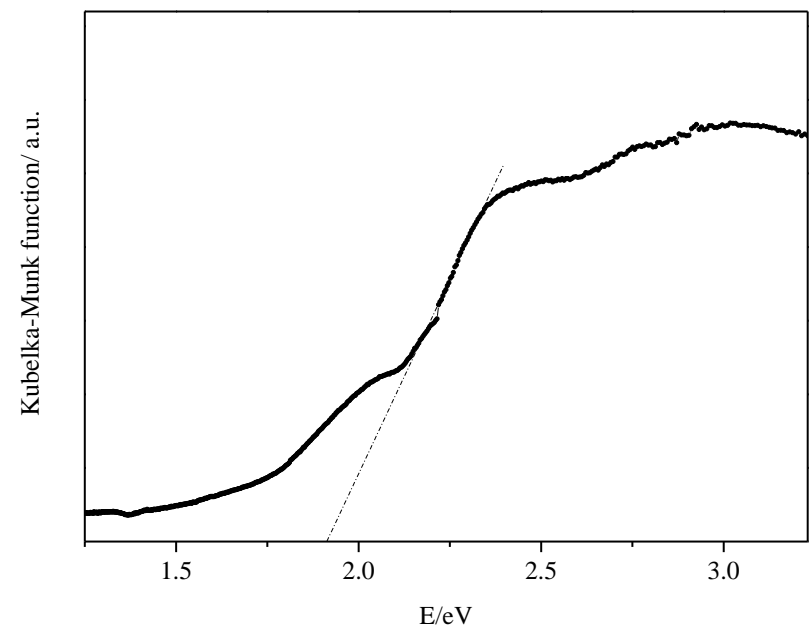

Figure 4. Optical absorption spectrum of $\left[\mathrm{C}_{7} \mathrm{H}_{10} \mathrm{~N}\right]\left[\mathrm{In}_{9} \mathrm{Se}_{14}\right]$. The dashed line shows the extrapolation from the high-energy end of the absorption edge used to determine the band gap.

In conclusion, $\left[\mathrm{C}_{7} \mathrm{H}_{10} \mathrm{~N}\right]\left[\mathrm{In}_{9} \mathrm{Se}_{14}\right]$ has an unique openframework structure, containing one-dimensional circular channels of $c a$. $6 \AA$ diameter. Our current efforts are directed towards the use of ion exchange to access the microporosity within this structure.

Acknowledgment The author thanks the UK EPSRC for an Advanced Research Fellowship.

Supporting Information Available: Crystallographic data in CIF format, FTIR and TGA data. This material is available free of charge via the Internet at http://pubs.ac.org.

\section{REFERENCES}

(1) (a) Cheetham, A.K.; Férey; G.; Loiseau, T. Angew. Chem., Int. Ed., 1999, 38, 3268. (b) Cundy, C.S.; Cox, P.A. Chem. Rev., 2003, 103, 663.

(2) (a) Li, J.; Chen, Z.; Wang, R. J.; Proserpio, D. M. Coord. Chem. Rev., 1999, 190-192, 707. (b) Sheldrick, W.S.; Wachhold, M. Coord.
Chem. Rev., 1998, 176, 211. (c) Feng, P.; Bu, X.; Zheng, N. Acc. Chem. Res., 2005, 38, 293.

(3) Ozin, G. A. Supramolecular Chem., 1995, 6, 125.

(4) Manos, M. J.; Chrissafis, K.; Kanatzidis, M. G. J. Am. Chem. Soc., 2006, 128,8875

(5) Zheng, N.; Bu, X.; Vu, H.; Feng, P. Angew. Chem. Int. Ed., 2005, 44, 5299.

(6) (a) Férey, G. Angew. Chem. Int. Ed., 2003, 42, 2576. (b) Bu, X.; Zheng, N.; Feng, P. Chem. Eur. J., 2004, 10, 3356.

(7) Slack, G.A., in CRC Handbook of Thermoelectrics, Chapter 34, Ed. D. M. Rowe, CRC Press, 1995.

(8) Wang, C.; Bu, X.; Zheng, N.; Feng, P. Chem. Commun., 2002, 1344.

(9) Cahill, C. L.; Ko, Y.; Parise, J.B. Chem. Mater., 1998, 10, 19.

(10) Zheng, N.; Bu, X.; Feng, P. Nature, 2003, 428.

(11) Wang, C.; Bu, X.; Zheng, N.; Feng, P. Angew. Chem. Int. Ed., 2002, $41,1959$.

(12) Manos, M. J.; Malliakas, C. D.; Kanatzidis, M. G. Chem. Eur. J., $2007,13,51$.

(13) A crystal (dimensions $0.04 \times 0.04 \times 0.2 \mathrm{~mm}^{3}$ ) was mounted on a glass fibre and X-ray intensity data collected using a Bruker X8 APEX 2 diffractometer with graphite monochromated $\mathrm{MoK}_{\alpha}$ radiation $(\lambda=0.71073 \AA)$ at $100 \mathrm{~K}$. The structure was solved by direct methods using the program SIR92 and models refined using CRYSTALS. The data were treated with SQUEEZE, to correct the effect of the disordered organic component.

(14) Diffuse reflectance measurements were collected using a Perkin Elmer Lambda $35 \mathrm{UV}$-Vis Spectrometer. $\mathrm{BaSO}_{4}$ powder was used as a reference and the absorption data were calculated from the reflectance data using the Kubelka-Munk function.

(15) Pfitzner A.; Lutz, H.D. J. Solid State Chem., 1996, 124, 305

(16) Hatzisymeon, K.G.; Kokkou, S.C.; Anagnostopoulos, A.N.; Rentzeperis, P.I., Acta Cryst. B, 1998, 54, 358.

(17) Rigoult, J.; Rimsky, A.; Kuhn, A. Acta Cryst. B, 1980, 36, 916.

(18) Hogg, J.H.C.; Sutherland, H.H.; Williams, D.J. Acta Cryst. B, 1973, $29,1590$.

(19) Spek, A.L. J. Appl. Cryst., 2003, 36, 7.

(20) Elemental analysis: found: $\mathrm{C}=3.58 \%, \mathrm{H}=0.32 \%, \mathrm{~N}=0.33 \%$; calc.: $\mathrm{C}=3.74 \%, \mathrm{H}=0.45 \%, \mathrm{~N}=0.62 \%$.

(21) Thermogravimetric analysis was performed using a DuPont Instruments 951 thermal analyser. Approximately $7 \mathrm{mg}$ of finely ground crystals were heated under a flow of dry nitrogen over the temperature range $25-400^{\circ} \mathrm{C}$ at a heating rate of $5^{\circ} \mathrm{C} \mathrm{min}^{-1}$

(22) (a) Zheng, N.; Bu, X.; Wang, B.; Feng, P. Science, 2002, 298, 2366. (b) Zheng, N.; Bu, X.; Feng, P. J. Am. Chem. Soc., 2003, 125, 1138.

(23) Madelung, O. Semiconductors: Data Handbook; Springer-Verlag: Berlin, 2004.

(24) Powell, A. V.; Lees, R. J. E.; Chippindale, A. M. J. Phys. Chem. Solids, 2007, accepted. 
The indium selenide $\left[\mathrm{C}_{7} \mathrm{H}_{10} \mathrm{~N}\right]\left[\mathrm{In}_{9} \mathrm{Se}_{14}\right]$ has been prepared under solvothermal conditions, and characterized by single crystal X-ray diffraction, thermogravimetry, elemental analysis, FTIR spectroscopy and UV-Vis diffuse reflectance. $\left[\mathrm{C}_{7} \mathrm{H}_{10} \mathrm{~N}\right]\left[\mathrm{In}_{9} \mathrm{Se}_{14}\right]$ has a unique open-framework structure, containing one-dimensional circular channels of ca. $6 \AA$ diameter.

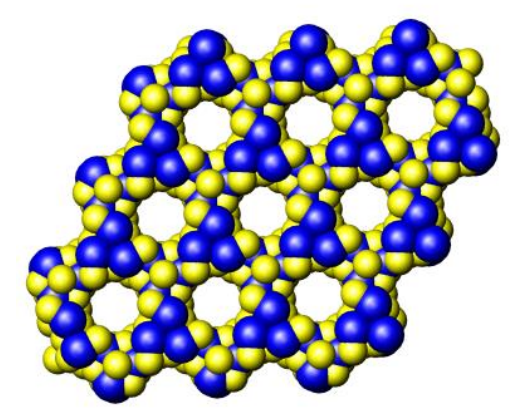

